\title{
Repetitive paroxysmal tachycardia originating in the left atrium
}

\author{
G. von Bernuth, G. G. Belz, and K. Schairer \\ From the Department of Paediatrics and the Section of Cardiology and Angiology, \\ Zentrum für Innere Medizin und Kinderheilkunde, University of Ulm, Germany
}

Three patients with repetitive supraventricular paroxysmal tachycardia are described, one of them with
an atrial septal defect in addition. All three patients were asymptomatic; two, however, had a striking
cardiomegaly (one of these is the patient with atrial septal defect). The electrocardiogram showed supraven-
tricular tachycardia of medium frequency as the predominant rhythm, interrupted by phases of normal sinus
rhythm of varying duration. The $P$ waves were present during tachycardia and suggested a left atrial pace-
maker. This was confirmed by comparison of right and left atrial (or pulmonary arterial wedge, respectively)
pressure curves during both normal sinus rhythm and supraventricular tachycardia.

Parkinson and Papp (1947) defined the clinical and electrocardiographic criteria of repetitive paroxysmal tachycardia. The ectopic pacemaker in this form of tachycardia may be located in the atria, in the atrioventricular junction, and in the ventricles. Chronicity, relatively slow frequency, and easy identification of $P$ waves allow discrimination of the repetitive from the more usual form of supraventricular tachycardia.

Within the past few years, we have seen 7 patients with supraventricular repetitive paroxysmal tachycardia whose electrocardiograms fulfilled the criteria for left atrial origin of the ectopic focus. In 3 of these patients, diagnostic heart catheterization was performed and confirmed the site of the ectopic pacemaker in the left atrium.

\section{Methods}

The electrocardiograms were registered by means of a Siemens Cardiorex $6 \mathrm{~T}$ recorder.

Right and left atrial or pulmonary arterial wedge pressures were measured consecutively using Cournand catheters (No. 6 or 7 F) or simultaneously (Case 2) using a Cournand double lumen catheter. They were recorded together with one or several standard electrocardiographic leads on a photographic recorder (Electronics for Medicine). Statham transducers $P 23 \mathrm{Db}$ were used as pressure transducers.

\section{Subjects}

The 3 patients were referred for diagnostic evaluation because of an irregular heart.

Received 24 January 1973.

\section{Case I}

This 7-month-old male infant had been delivered by caesarean section because of irregular heart sounds. His birthweight was $3000 \mathrm{~g}$. After birth, rapid and irregular cardiac action continued, but the child thrived normally. Physical findings were unremarkable except for the cardiac rhythm which varied abruptly between short phases with approximately 100 beats a minute and longer periods with approximately 180 beats a minute. The chest $x$-ray repeatedly showed a grossly enlarged heart with a cardiothoracic ratio of 69 per cent but normal pulmonary vasculature. Right heart catheterization was performed, as in the absence of clinically recognizable heart failure and in the presence of only moderate tachycardia, the infant's cardiomegaly remained hard to explain. All intracardiac pressures and $\mathrm{O}_{2}$ concentrations were within normal limits. Biplane selective angiocardiography revealed moderate dilatation of all cardiac chambers.

\section{Case 2}

This I8-month-old girl was born 2 weeks before term with a birthweight of $2280 \mathrm{~g}$ and normal development. At the age of I year the parents noticed first that the child's heart beat was strong and rapid; otherwise, she appeared healthy. Physical examination revealed a resting tachycardia of 170 to 180 beats a minute which decreased only during sleep and premedication for cardiac catheterization to 100 to 120 beats a minute. At this rate the first heart sound was normal while the second heart sound appeared widely and constantly split. A grade 2/6 left parasternal systolic murmur was heard. All other physical findings were normal. The chest $x$-ray showed a much enlarged heart with increased pulmonary vascular markings. Cardiac catheterization 
revealed a secundum type atrial septal defect with 50 per cent left-to-right shunt and normal pressures in all cardiac chambers except for somewhat high mean pressures in the right and left atrium (II and $13 \mathrm{mmHg}$, respectively).

\section{Case 3}

This 17 -year-old young man was found to have a rapid and irregular heart. He was in good physical condition and did not notice his arrhythmia. Physical examination showed a normally developed young man with a rapid irregular heart of approximately 140 beats a minute. The first heart sound varied in intensity, and a grade 2/6 left parasternal systolic murmur was heard. All other physical findings as well as the chest $x$-ray were normal. In order to exclude cardiac abnormality catheterization of the right and, via a patent foramen ovale, also the left heart was performed. All pressures and $\mathrm{O}_{2}$ saturations were normal.

\section{Electrocardiograms}

In the electrocardiograms of all 3 patients, the periods of tachycardia were dominant. Between these phases, short periods or, in Case 3, only single cardiac cycles with normal sinus rhythm were found. The QRS-T complexes in all cases were identical during normal sinus rhythm and during tachycardia.

In Case I (Fig. I), the tachycardia showed a frequency between 150 and 185 beats a minute. The $P$ waves during tachycardia were negative in leads I, II, aVL, and aVF as well as V5 and V6. The axis, therefore, pointed to the right, superiorly and anteriorly. The $P Q$ interval was 0.12 sec during both normal sinus and the ectopic rhythm. The QRS-T complexes were unremarkable.

In Case 2 (Fig. 2), the heart rate during the ectopic rhythm was approximately 170 beats a minute but decreased to 120 beats a minute during sedation. The $P$ waves during these phases were negative in leads $I$, aVR, and aVL, predominantly negative in leads VI to $V_{4}$, and biphasic in lead V6. Thus, the $P$ axis pointed to the right, inferiorly and posteriorly. The $P Q$ interval was 0.12 sec during both normal sinus and the ectopic rhythm. During normal sinus rhythm, the $\mathbf{P}$ waves in leads II, III, and aVF were high and peaked, and lead VI showed a rsR'-complex, suggesting right atrial enlargement and diastolic overload of the right ventricle.

In Case 3 (Fig. 3), the heart rate ranged from 140 to 150 beats a minute, interrupted by a few normal sinus

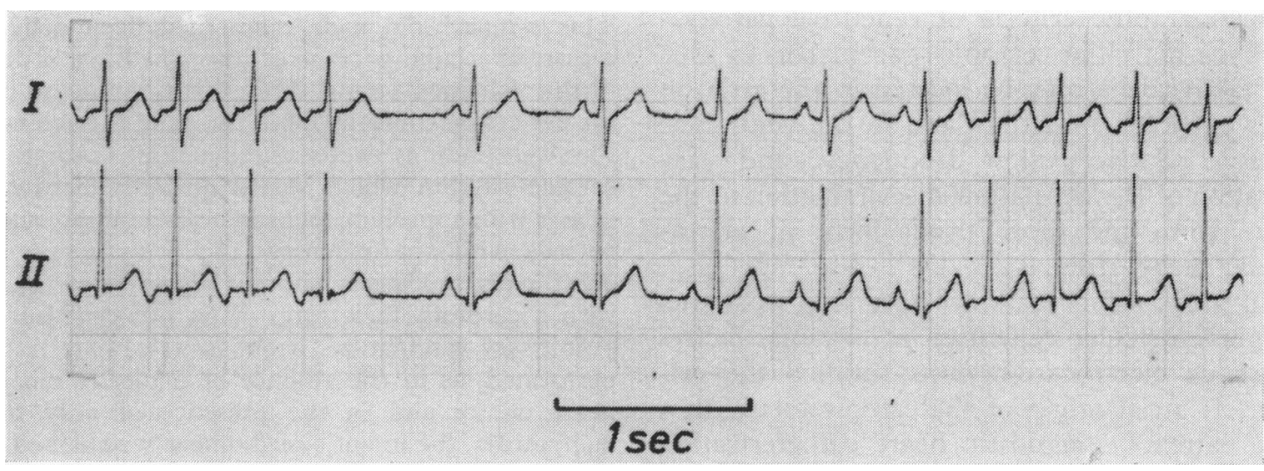

FIG. I Leads I and II of Case I during spontaneous change from ectopic atrial rhythm to normal sinus rhythm and back to ectopic rhythm.

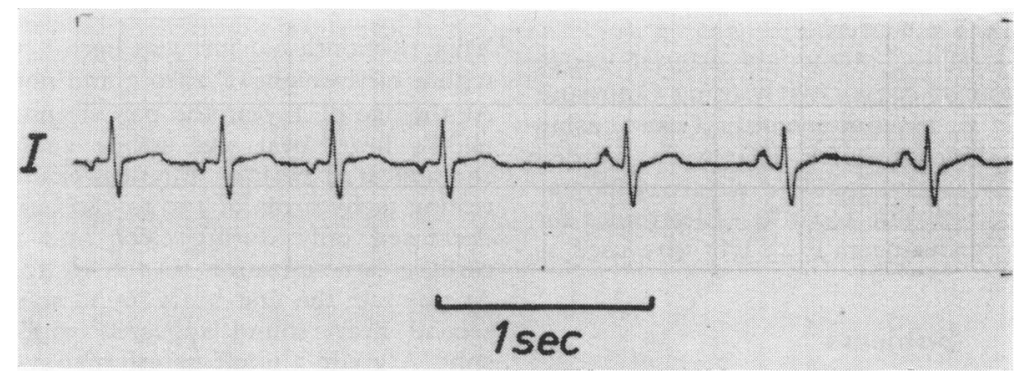

FI G. 2 Lead I of Case 2 during spontaneous change from ectopic atrial rhythm to normal sinus rhythm. 
TABLE I Summary of deflection of $P$ waves during normal sinus rhythm and ectopic atrial rhythm

\begin{tabular}{|c|c|c|c|c|c|c|c|c|c|c|c|c|}
\hline \multirow{2}{*}{$\begin{array}{l}\text { Case } \\
\text { No. }\end{array}$} & \multirow[t]{2}{*}{ Rhythm } & \multirow{2}{*}{$\begin{array}{l}\text { Heart rate } \\
\text { (beats/min) }\end{array}$} & \multirow{2}{*}{$\begin{array}{l}P Q \text { interval } \\
(\text { msec })\end{array}$} & \multicolumn{8}{|c|}{ Main deflection of $P$ wave in lead } & \multirow{2}{*}{$\begin{array}{l}F A_{\mathrm{P}^{\star}} \\
\text { (degrees) }\end{array}$} \\
\hline & & & & $I$ & $I I$ & $I I I$ & $a V R$ & $a V L$ & $a V F$ & $V_{1}$ & $V_{6}$ & \\
\hline $\mathbf{I}$ & $\begin{array}{l}\text { Normal sinus } \\
\text { Ectopic atrial }\end{array}$ & $\begin{array}{l}100 \\
150-185\end{array}$ & $\begin{array}{l}0.12 \\
0.12\end{array}$ & $\begin{array}{l}+ \\
-\end{array}$ & $\begin{array}{l}+ \\
-\end{array}$ & $\begin{array}{l} \pm \\
\pm\end{array}$ & $\overline{+}$ & $\begin{array}{l}+ \\
-\end{array}$ & $\begin{array}{l}+ \\
-\end{array}$ & \pm & $\begin{array}{l}+ \\
-\end{array}$ & $\begin{array}{r}+30 \\
-150\end{array}$ \\
\hline 2 & $\begin{array}{l}\text { Normal sinus } \\
\text { Ectopic atrial }\end{array}$ & $\begin{array}{l}100 \\
170\end{array}$ & $\begin{array}{l}0.12 \\
0.12\end{array}$ & $\begin{array}{l}+ \\
-\end{array}$ & $\begin{array}{l}+ \\
+\end{array}$ & $\begin{array}{l}+ \\
+\end{array}$ & $\begin{array}{l}- \\
-\end{array}$ & \pm & $\begin{array}{l}+ \\
+\end{array}$ & $\overline{-}$ & $\begin{array}{l}+ \\
\pm\end{array}$ & $\begin{array}{r}+50 \\
+100\end{array}$ \\
\hline 3 & $\begin{array}{l}\text { Normal sinus } \\
\text { Ectopic atrial }\end{array}$ & $\begin{array}{r}60 \\
150\end{array}$ & $\begin{array}{l}0.13 \\
0.13\end{array}$ & $\begin{array}{l}+ \\
\pm\end{array}$ & $\begin{array}{l}+ \\
-\end{array}$ & \pm & $\overline{+}$ & $\begin{array}{l}+ \\
+\end{array}$ & $\begin{array}{l}+ \\
-\end{array}$ & \pm & $\begin{array}{l}+ \\
-\end{array}$ & $\begin{array}{l}+30 \\
-90\end{array}$ \\
\hline
\end{tabular}

* $F A_{P}, P$ axis in the frontal plane.

beats. During the ectopic rhythm the $\mathbf{P}$ waves were biphasic in lead I and negative in leads II, III, aVF, V5, and V6. In lead VI, the $P$ waves showed a typical 'dome and dart' configuration described by Mirowski, Neill, and Taussig (1963) as specific for left atrial rhythm. The $\mathbf{P}$ axis pointed slightly to the right, superiorly and anteriorly. The $P Q$ interval ranged around $0.13 \mathrm{sec}$ during the ectopic rhythm as well as during the normal sinus beats.

Table I gives a summary of the deflection of the $\mathbf{P}$ waves during normal sinus rhythm and ectopic atrial rhythm in the 3 patients.

\section{Analysis of atrial pressure curves}

In all three cases, right and left atrial pressures (Cases 2 and 3) or right atrial and pulmonary arterial wedge pressures (Case I) could be recorded during both normal sinus rhythm and the ectopic rhythm. In Table 2 the intervals between the beginning of the $P$ wave in the electrocardiogram and the peak of the a wave in the right and left atrium or pulmonary arterial wedge position, during both rhythms, are summarized. During normal sinus rhythm, this interval in Cases $I$ and 3 is shorter in the right than in the left atrium or pulmonary arterial wedge position. In Case 2, this interval is equal in both atria. This implies that in Cases $I$ and 3 the right atrium contracts before the left one, while in Case 2 both atria contract simultaneously. During the ectopic phases, the interval is shorter in all three cases in the left atrium by 25 to $50 \mathrm{msec}$ than in the right atrium. This implies that during the ectopic phases the left atrium contracts before the right. The change in the sequence of atrial contractions with changing rhythm is evident in Fig. 4.

\section{Discussion}

It has been known for many years that, during sinus rhythm, the right atrium contracts before the left one (Fredericq, 1906; Bachmann, 1916). This rule was recently confirmed in the majority of a large group of patients with various cardiac diseases (Belz et al., r973a). However, in the same group of patients it was found that this sequence was inverted in about 20 per cent of all cases. The analysis of single cases with spontaneous variation between normal sinus rhythm and an ectopic supraventricular rhythm suggested that, in the presence of confirmatory electrocardiographic data, an inversion of the normal sequence of atrial contractions signified a left atrial pacemaker (Slany and Mösslacher, 1970; Belz, Olesch, and Heesemann, I97I; von Bernuth and Belz, 1972). When a left atrial rhythm was induced by electrical stimulation of the left atrial endocardium it was shown that the left atrium contracted regularly before the right one (Belz et al., I973b). Thus, a left atrial pacemaker may be assumed when it can be shown that

TABLE 2 Intervals between beginning of $P$ wave in electrocardiogram and peak of a wave in right and left atrial pressure pulse

\begin{tabular}{|c|c|c|c|c|c|c|}
\hline \multirow{2}{*}{$\begin{array}{l}\text { Case } \\
\text { No. }\end{array}$} & \multicolumn{3}{|c|}{ Normal sinus rhythm } & \multicolumn{3}{|c|}{ Ectopic atrial rhythm } \\
\hline & $\begin{array}{l}P-a_{\mathrm{Ad}} \\
\left(\Delta_{1}\right) \mathrm{msec}\end{array}$ & $\begin{array}{l}P-a_{\mathrm{As}} \\
\left(\Delta_{2}\right)^{\star} \mathrm{msec}\end{array}$ & $\begin{array}{l}\Delta_{2}-\Delta_{1} \\
m s e c\end{array}$ & $\begin{array}{l}P-a_{\text {Ad }} \\
\left(\Delta_{3}\right) \text { msec }\end{array}$ & $\begin{array}{l}P-a_{\mathrm{As}} \\
\left(\Delta_{4}\right)^{\star} \mathrm{msec}\end{array}$ & $\begin{array}{l}\Delta_{4}-\Delta_{3} \\
m s e c\end{array}$ \\
\hline I & 95 & IIO & +15 & 105 & 70 & -35 \\
\hline 2 & 150 & 150 & \pm 0 & 190 & 140 & -50 \\
\hline 3 & 100 & 160 & +60 & I 40 & II 5 & -25 \\
\hline
\end{tabular}

$P-a_{A d}$, interval between beginning of $P$ wave and peak of a wave in the right atrium.

$P-a_{A s}$, interval between beginning of $P$ wave and peak of a wave in the left atrium.

$\star$ To compensate for the delay of pulmonary arterial capillary pressure with respect to left atrial pressure, $60 \mathrm{msec}$ were subtracted from $\Delta_{2}$ and $\Delta_{4}$ in Case I (Wolter et al., 1953). 


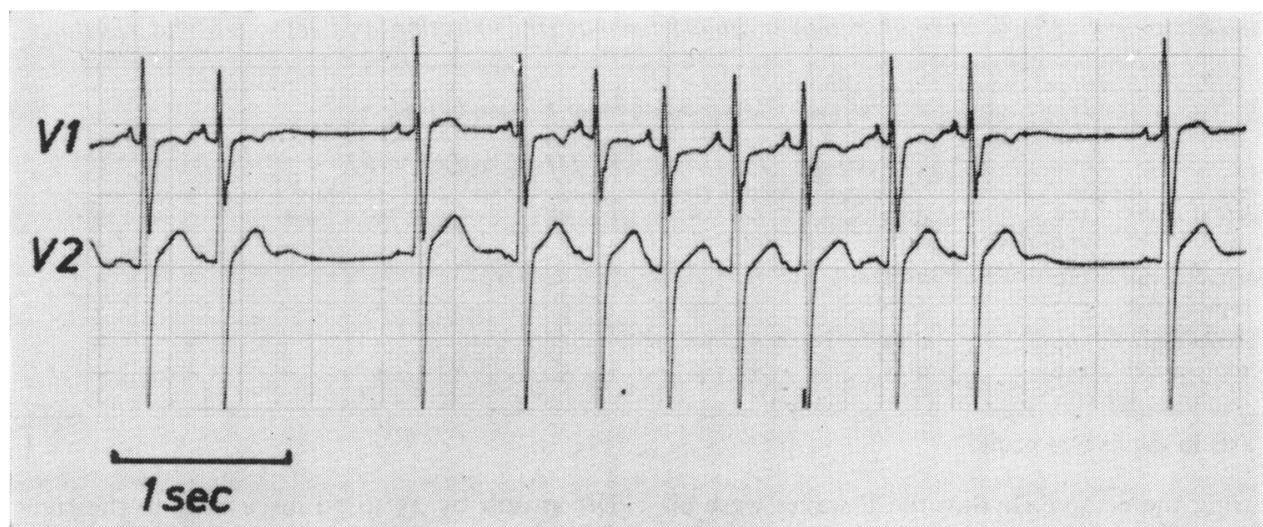

FIG. 3 Leads VI and V2 of Case 3 showing predominantly an ectopic atrial rhythm interrupted by two normal sinus beats (beats 3 and II). Note the 'dome and dart' configuration of the $P$ waves in VI during the ectopic atrial rhythm.

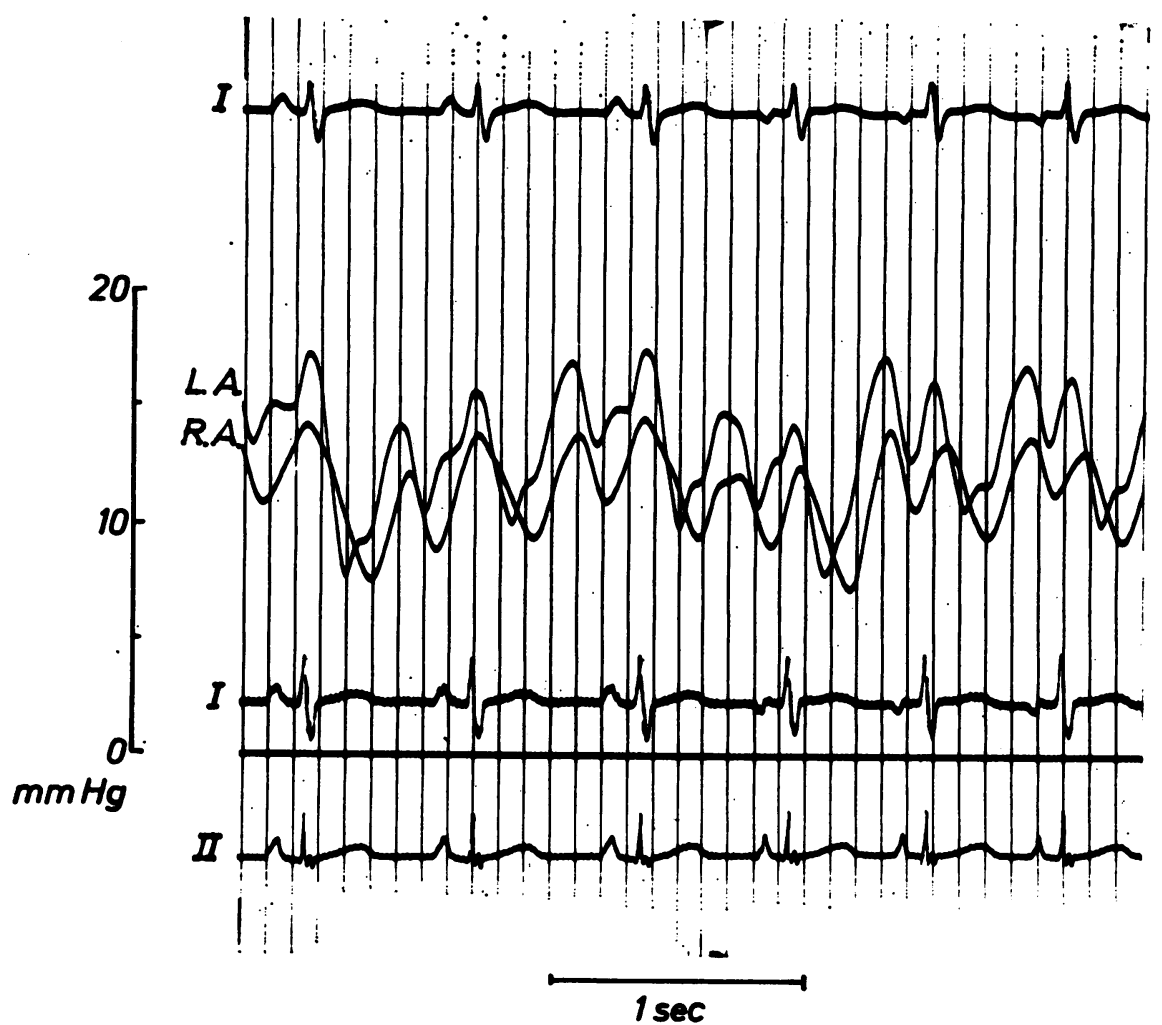

FI G. 4 Simultaneous right and left atrial pressure tracings and leads I and II during spontaneous change from normal sinus rhythm to ectopic atrial rhythm in Case 2. During normal sinus rhythm the right and left atrial a waves coincide in time while during the ectopic atrial rhythm the left atrial a waves precede the right atrial a waves. $L A$, left atrial pressure; $R A$, right atrial pressure. 
the left atrium contracts before the right one during the ectopic rhythm in question, but contracts after or simultaneously with the right one during normal sinus rhythm. The electrocardiographic criteria described by Mirowski (Mirowski et al., 1963; Mirowski, I966, 1967) as typical for left atrial rhythm are helpful but not specific (Massumi and Tawakkol, 1967; Harris et al., I968; Lau et al., 1970).

The three patients here described fulfil the postulated electrocardiographic and haemodynamic criteria for a left atrial pacemaker during the ectopic supraventricular rhythm. Based on the results of elective stimulation (Harris et al., 1968) and on vectorial considerations one may assume that the ectopic pacemaker in Cases $I$ and 3 lies close to the junction of the right lower pulmonary vein with the left atrium. It is known that automatic cells exist in this area (Hoffman and Cranefield, 1964). In Case 2, whose $\mathbf{P}$ axis during the episodes of tachycardia points to the right, inferiorly and posteriorly, the ectopic pacemaker may be assumed to lie superiorly and anteriorly in the left atrium (Mirowski, 1967).

The clinical symptomatology and the duration of the repetitive supraventricular paroxysmal tachycardia depend on the frequency and persistence of the ectopic pacemaker. It does not seem that these parameters differ in the left atrial form from other types of repetitive supraventricular paroxysmal tachycardia. The left atrial localization of the ectopic pacemaker is, therefore, more of physiological interest than of practical importance.

\section{References}

Bachmann, G. (19I6). The interauricular time interval. American fournal of Physiology, 4I, 309.

Belz, G. G., Olesch, K., and Heesemann, E. (197I). Elektrokardiographische Beobachtungen und intraatriale Druckmessungen bei einem Patienten mit linkem Vorhofrhythmus. Herz/Kreislauf, 3, 18 .
Belz, G. G., Röhl, D., von Bernuth, G., Wolf, G., and Stauch, M. (1973a). Beziehungen zwischen hämodynamischen und elektrokardiographischen Parametern und der zeitlichen Folge der a-Wellen im rechten und linken Vorhof. Zeitschrift für Kardiologie, 62, 175.

Belz, G. G., von Bernuth, G., Hofstetter, R., Röhl, D., and Stauch, M. (1973b). Temporal sequence of right and left atrial contractions during spontaneous sinus rhythm and paced left atrial rhythm. British Heart fournal, 35, 284.

Fredericq, L. (1906). La pulsation du coeur du chien. Archives Internationales de Physiologie, 4, 57.

Harris, B. C., Shaver, J. A., Gray, S., Kroetz, F. W., and Leonard, J. J. (1968). Left atrial rhythm; experimental production in man. Circulation, 37, 1000.

Hoffman, B. F., and Cranefield, P. F. (1964). The physiological basis of cardiac arrhythmias. American fournal of Medicine, 37, 670 .

Lau, S. H., Cohen, S. I., Stein, E., Haft, J. I., Rosen, K. M., and Damato, A. N. (1970). P waves and $P$ loops in coronary sinus and left atrial rhythms. American Heart fournal, 79, 201.

Massumi, R., and Tawakkol, A. A. (1967). Direct study of left atrial $P$ waves. American fournal of Cardiology, 20, 33I.

Mirowski, M. (1966). Left atrial rhythm. Diagnostic criteria and differentiation from nodal arrhythmias. American fournal of Cardiology, 17, 203.

Mirowski, M. (1967). Ectopic rhythms originating anteriorly in the left atrium. American Heart fournal, 74, 299.

Mirowski, M., Neill, C. A., and Taussig, H. B. (1963). Left atrial ectopic rhythm in mirror-image dextrocardia and in normally placed malformed hearts. Report of twelve cases with 'dome and dart' $P$ waves. Circulation, 27, 864.

Parkinson, J., and Papp, C. (1947). Repetitive paroxysmal tachycardia. British Heart fournal, 9, 24I.

Slany, J., and Mösslacher, H. (1970). Zur Frage des linken Vorhofrhythmus. Zeitschrift für Kreislaufforschung, 59, 177.

von Bernuth, G., and Belz, G. G. (1972). Korrelation hämodynamischer und elektrokardiographischer Befunde bei einer Patientin mit linkem Vorhofrhythmus. Zeitschrift für Kreislaufforschung, 61, 528.

Wolter, H. H., Bayer, O., Loogen, F., and Rippert, R. (1953). Die sogenannte Pulmonalkapillardruckkurve und ihre Beziehung zur Druckkurve des rechten und linken Vorhofs. Cardiologia, 23, 319.

Requests for reprints to Dr. G. von Bernuth, Universitäts-Kinderklinik, D 79 Ulm (Donau), Prittwitzstrasse, Germany. 